\title{
The carboxyterminus of human c-myb protein stimulates activated transcription in trans
}

\author{
Gerd Vorbrueggen, Frank Kalkbrenner+ ${ }^{+}$Stephan Guehmann and Karin Moelling * \\ Max-Planck-Institut für Molekulare Genetik, Abteilung Schuster, Ihnestrasse 73, D-14195 Berlin, \\ Germany
}

Received April 25, 1994; Revised and Accepted June 8, 1994

\begin{abstract}
The cellular c-myb gene encodes a transcription factor composed of a DNA-binding domain, a transactivating domain and a regulatory domain located at its carboxy (C-) terminus. The latter one is deleted in the transforming viral protein v-Myb. Here we show that deletion of the C-terminus of $\mathrm{c}-\mathrm{Myb}$ increases the transcriptional transactivation activity of c-Myb defining it as cis-acting negative regulatory domain. Cotransfection of the $C$ terminus in an in vivo competition assay causes stimulation of the transcriptional activity of various $v$ and c-Myb expression constructs in trans. The effect is dose-dependent and independent of the kind of DNAbinding domain, since c-Myb as well as GAL4-c-Myb chimaeras can be stimulated in trans. Other transcription factors, such as GAL4-VP16, GAL4, c-Jun or C/EBP $\beta$ are also stimulated by the cotransfected Cterminus. In contrast, human B-Myb is not stimulated by the $c-M y b$ C-terminus in trans. The data suggest that the C-terminus of $\mathrm{c}-$ Myb may interact with a cellular inhibitor which is part of the protein complex mediating activated transcription and may stimulate in trans by sequestering away such an inhibitor. Binding of $\mathrm{C}-\mathrm{Myb}$ to a putative inhibitor would explain differences between C-Myb in comparison to B- and v-Myb in transcriptional regulation.
\end{abstract}

\section{INTRODUCTION}

The c-myb proto-oncogene is the cellular homologue of the $v$ myb oncogene originally found in avian myeloblastosis virus, AMV, and E26 retroviruses $(1,2)$. Both, v-Myb and c-Myb are nuclear proteins (3) and bind to the DNA sequence T/CAAC(G/C)G $(4,5)$ which is present on cellular genes such as mim-1 (6), the hu-c-myc regulatory region (7), or the viral enhancer HIV-LTR (8). The v-Myb and c-Myb proteins contain an acidic transactivation domain $(9,10)$. Both can activate transcription of several reporter plasmids $(11,12,6,7)$.

Recently, a new myb homologue, called B-myb, has been cloned from different organisms $(13,14,15,16)$, encoding a protein of $\sim 110 \mathrm{kD}$. The protein shows a strong aminoacid sequence homology in its DNA-binding domain with c-Myb, and is able to bind to the c-Myb-specific DNA-binding motif (16). In transient transfection assays hu-B-Myb is able to activate a promotor in a mechanism depending on Myb DNA-binding sites $(17,18)$ as well as by a mechanism independent of DNA-binding sites as in the case of the HSP-70 promotor (19).

The $\mathrm{v}-\mathrm{Myb}$ oncoproteins are in comparison to the $\mathrm{c}-\mathrm{Myb}$ protein truncated at their amino- as well as carboxy-(C-)-termini which are replaced by sequences encoded by the viral gag and env genes, respectively (20). The v-Myb protein of AMV comprises in addition 11 amino acid substitutions compared to c-Myb. It has been shown, however, that neither addition of gag and env sequences nor presence of the mutations are required for transformation by v-Myb $(21,22,23)$.

Deletion of C-terminal sequences leads to an enhanced DNAbinding affinity (24). In addition the C-terminus of c-Myb contains two non-overlapping negative regulatory domains $(25,26,10)$. A heptad leucine repeat located between aminoacid residues 373 to 407 is thought to negatively regulate the transcriptional activity by homodimer formation of $\mathrm{c}-\mathrm{Myb}$ which results in inactivation (27). The second negative regulatory domain is located between aminoacid residues 495 and 640 , which are deleted in the transforming v-Myb $(10,28)$. C-terminal truncations are also found in different transformed cell lines $(29,30,31)$. Furthermore, c-Myb expressing constructs lacking the C-terminus exhibit the ability to transform haematopoietic cells in vitro $(32,33,34)$.

Here we analyze the role of the C-terminus of hu-c-Myb in transcriptional regulation. An in vivo competition assay using different parts of the $\mathrm{C}$-terminus expressed individually has been used to study its contribution to the transcriptional activity. The results presented here indicate that the cis-acting C-terminus of hu-c-Myb as part of the full-length protein negatively regulates transcriptional activation presumably by binding to a cellular inhibitory factor. When the C-terminus is expressed individually and tested in transient cotransfection assays in trans it is able to enhance transcription by c-Myb, presumably by titrating out the putative cellular inhibitory factor. This inhibitor seems to be part of the general initiation complex of the RNA-polymerase II, since various activators can be stimulated by the C-terminus

\footnotetext{
*To whom correspondence should be addressed at: Institut für Medizinische Virologie,Universität Zürich, CH-8028 Zürich, Switzerland

+Present address: Instirut für Pharmakologie der Freien Universität Berlin, Thielallee 69/73, D-14195 Berlin, Germany
} 
in trans. In contrast, the activity of B-Myb is not influenced. These findings can explain differences of transactivation properties between $\mathrm{v}$ - or B-Myb compared to $\mathrm{c}-\mathrm{Myb}$.

\section{MATERIAL AND METHODS}

\section{Plasmids}

Effector plasmids. Effector plasmids pHM1, expressing the $\mathrm{p} 75$ hu-c-Myb protein, and pHM5, expressing a C-terminal deletion mutant of hu-c-Myb with a molecular weight of $42 \mathrm{kD}$, have been described (7). An AMV v-Myb expressing construct (pVM1) without the nucleotides coding for gag and env aminoacid residues was generated by PCR using a $5^{\prime}$ oligonucleotide containing an ATG start codon which replaces the last codon of the gag fusion protein and a v-myb plasmid (pVM2) (1) as a template. The PCR product was cloned into the expressing vector pECE (35). The C-terminus of hu-c-Myb (pMC1) was generated by PCR using a 5'oligonucleotide, which contains an ATG start codon instead of aminoacid (aa) 440 of hu-c-myb sequence and a $3^{\prime}$ oligonucleotide which anneals at the $3^{\prime}$ untranslated region of hu-c-myb. The resulting fragment was cloned into the expression vector $\mathrm{pECE}$ resulting in the plasmid pMC1. pGM5 expressing a protein corresponding to pHM5 has been described (10). For cloning C-terminal deletion mutants, the BglII / XbaI fragment of the C-terminus expression plasmid pMC1 was replaced by the corresponding fragments of pGM2 and pGM3 (10), resulting in pMC2 (expressing aa 441-590 of hu-c-Myb) and pMC3 (expressing aa $441-566$ of hu-c-Myb), respectively. The C-terminal deletion mutants pMC4 and pMC5 were cloned by PCR using $5^{\prime}$ oligonucleotides containing an ATG start codon instead of aa 482 and 512, respectively and a $3^{\prime}$ oligonucleotide which anneals at the $3^{\prime}$ untranslated region of hu-c-myb. For generating the GAL4-C-terminus expression construct pMC6 the plasmid $\mathrm{pMCl}$ was restricted with $\mathrm{KpnI}$ and $\mathrm{Xbal}$ and the fragment was inserted into the GALA (1 - 147) fusion expressing vector pSG424 (36). The pMC7 construct was constructed using PCR using a $5^{\prime}$ oligonucleotide which contains a BgIII site instead of the codons for aminoacid residues 565 and 566. With this additional site an internal deletion between aminoacid residues 495 and 566 was cloned. Effector plasmids containing the transactivation domain of hu-c-Myb (aa 275-327) (10), the transactivation domain II of GAL4 (aa 768-881) (37) or the transactivation domain of VP-16 (aa 413-490) (38) were fused to the DNA-binding domain of GAL4 (aa 1-147) as have been described (37). The control plasmid pGM13 contains aminoacid residues $1-147$ of GAL4 (37). The hu-c-Jun expressing construct pHJ1 was generated by cloning the HindIII/EcoRI fragment of RSVjun (39) into the $\mathrm{pECE}$ vector. The C/EBP $\beta$ construct is described by Cao et al. (40). The hu-B-Myb expressing construct pBM1 was obtained by cloning a HindIII/XbaI fragment from the plasmid pAT-B18-Bmyb (41) into the pECE vector. All constructs cloned by PCR were verified by sequencing.

Reporter plasmids. The reporter plasmid used for the GALA-Myb expressing effector plasmids contains $13 \mathrm{GAL} 4$ binding sites (bs) cloned into the MMTV-LTR which was fused upstream of the CAT gene (37). The reporter plasmid $3 \times$ ATk Luc contains the high affinity binding site of the mim-1 promotor (site $A$ ) three times repeated upstream of a herpes simplex virus thymidine kinase $(\mathrm{Tk})$ minimal promotor $(-81$ to +52$)$ and a luciferase gene (6). The $3 \times$ TRETk CAT reporter contains three TRE elements of the collagenase promotor upstream of a herpes simplex virus thymidine kinase $(\mathrm{Tk})$ minimal promotor $(-109$ to +57 ) and a CAT gene, which was kindly provided by Peter Angel. The pM82 construct (42) consists of the cMGF promotor $(-82$ to +1$)$ in front of a luciferase gene, which was kindly provided by Achim Leutz.

\section{Transfection, CAT and luciferase assay}

Transfections of adherent HeLa or COS- 7 cells $\left(2 \times 10^{6}\right.$ cells per $10 \mathrm{~cm}$ plate) were performed by $\mathrm{CaPO}_{4}$ coprecipitation as described (7). CAT activity was measured by determination of acetylated $\left[{ }^{14} \mathrm{C}\right]$ chloramphenicol by scanning thin layer chromatography plates with a Phosphoimager (Molecular Dynamics). Luciferase activity was determined as described by de Wet et al. (43) using a Berthold luminometer (LB 9501). RSV- $\beta$-GAL control-plasmid $(0,5 \mu \mathrm{g}$ in Cos-7 and $2 \mu \mathrm{g}$ in HeLa cells) was used as internal standard except for figure $6 \mathrm{~B}$, where $2 \mu \mathrm{g}$ Tk- $\beta$-Gal was used. The $\beta$-galactosidase activity was quantitated by using chlorophenol-red- $\beta$-D-galactopyranoside as substrate, following the manufacturer's instructions (Boehringer Mannheim). CAT-, luciferase and $\beta$-galactosidase activity were determined 36 to $48 \mathrm{~h}$ after transfection and the histograms show the average CAT-conversion or luciferase-light units from at least three independent experiments, which were normalized in respect of $\beta$-galactosidase activity. Standard deviations are shown and the relative activities are listed referring to the activity of the cotransfection of reporter and expression plasmid without insert (pECE) which was set 1.

All transfection experiments were performed at least in four independent experiments, with different $\mathrm{CsCl}$-preparations of plasmid DNA, whereby the relative efficiencies within each experiment were reproducible. Transfection of COS-7 and adherent HeLa-cells led to similar results, whereby the expression of the $3 \times$ ATk Luc reporter plasmid in COS-7 cells were up to fivefold higher. Therefore most of the experiments with this luciferase reporter plasmid were performed in COS-7 cells.

\section{Western blot}

Transfections of COS-7 cells were performed by $\mathrm{CaPO}_{4}$ coprecipitation, the cells were lysed after 48 hours in samplebuffer and cellular lysates equivalent to $1 \times 10^{6}$ cells were applied per lane. Protein expression was determined as described (7) except for using the ECL blot system (Amersham) for detection, following the manufacturer's instructions.

\section{RESULTS}

The C-terminus of human c-Myb functions as a negatively regulating domain in cis but enhances activated transcription in trans

In a previous study we demonstrated that the transactivating effect of the human c-Myb protein, in which its authentic DNA-binding domain had been replaced by that of the yeast transcriptional transactivator GAL4, was almost undetectable with the entire protein but was high when parts of the C-terminus of c-Myb were deleted (10). Here we tried to elucidate the mechanism of action of the putative negative regulatory elements in the C-terminus of the human c-Myb protein.

In order to analyze the function of the C-terminus we first tested the Myb protein with its authentic DNA-binding domain. Therefore human $\mathrm{c}-\mathrm{Myb}$, a C-terminal truncated mutant and AMV v-Myb were characterized in transient transfection assays with the reporter plasmid $3 \times$ ATk Luc containing three high- 


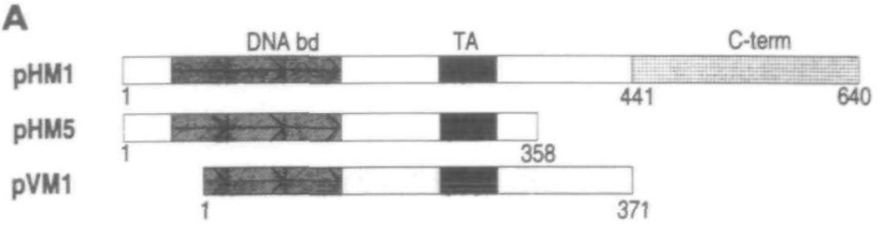

reporter: 3xATk LUC

$3 \times$ Oligo A (mim-pro) $-90 \quad \longrightarrow$ LuC

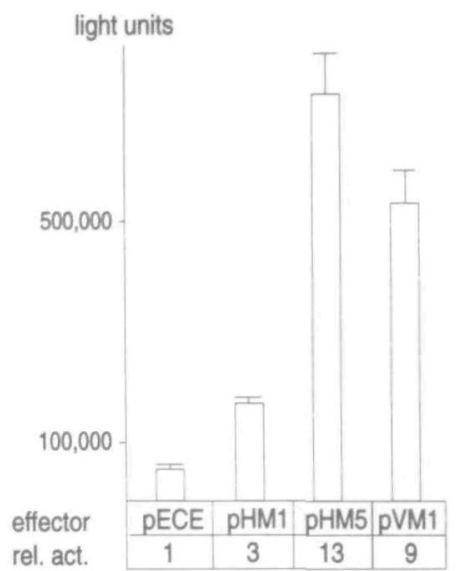

Figure 1. (A) Analysis of the transcriptional activity of hu-c-Myb (pHMl), a C-terminal truncation mutant (pHM5) and AMV v-Myb (pVM1). Schematic diagrams of the proteins tested are shown at the top, the DNA-binding domain is indicated by DNA bd with the three repeats (arrows, hatched), the transactivation domain by TA (black) and the C-terminus, corresponding to the sequences deleted in AMV v-Myb, by C-term (squared). The v-Myb protein (pVM1, grey) corresponds to the AMV v-Myb except that it does not contain viral gag or env sequences. The reporter plasmid $3 \times A T k$ Luc consists of a threefold repeat of the A motif of the mim-1 promotor, a minimal Tk promotor and the luciferase gene (6). pECE, pHM1, pHM5, or pVM1 ( $1 \mu \mathrm{g}$ each) as first effector plasmids were cotransfected with the $3 \times$ ATk Luc reporter plasmid $(3 \mu \mathrm{g})$ into adherent COS-7 cells. (B) Expression of various Myb proteins. In lanes 1 to $420 \mu \mathrm{g}$ of the indicated effector plasmids were transfected into COS-7 cells. Cellular lysate equivalent to $1 \times 10^{6}$ cells were applied per lane and the proteins were detected with a rabbit serum (1303) directed against the central part of c-Myb. Numbers to the left indicate molecular weight markers in $\mathrm{KD}$.

affinity Myb binding sites upstream of a herpes simplex virus thymidine kinase (Tk) minimal promotor and a luciferase (Luc) gene (6). The average of at least three independent experiments were determined whereby the transfection efficiencies were normalized in respect to the activity of a cotransfected RSV- $\beta-G-$ AL construct, which served as internal standard throughout this study.

Figure 1A shows that transactivation by the full-length c-Myb (pHM1) leads to only modest transcriptional activity whereas the C-terminally truncated mutant (pHM5) leads to enhanced activity compared to pHM1. The AMV v-Myb-expressing construct (pVM1) exhibits an intermediate transactivating activity. A control reporter plasmid lacking Myb DNA-binding sites did not give rise to a Myb-dependent expression of the reporter gene (data not shown). These results are in agreement with those of previous transfection studies performed with GAL4-c-Myb chimaeras (10). The stimulatory effect of the C-terminal truncations are not due to differences in protein expression, since
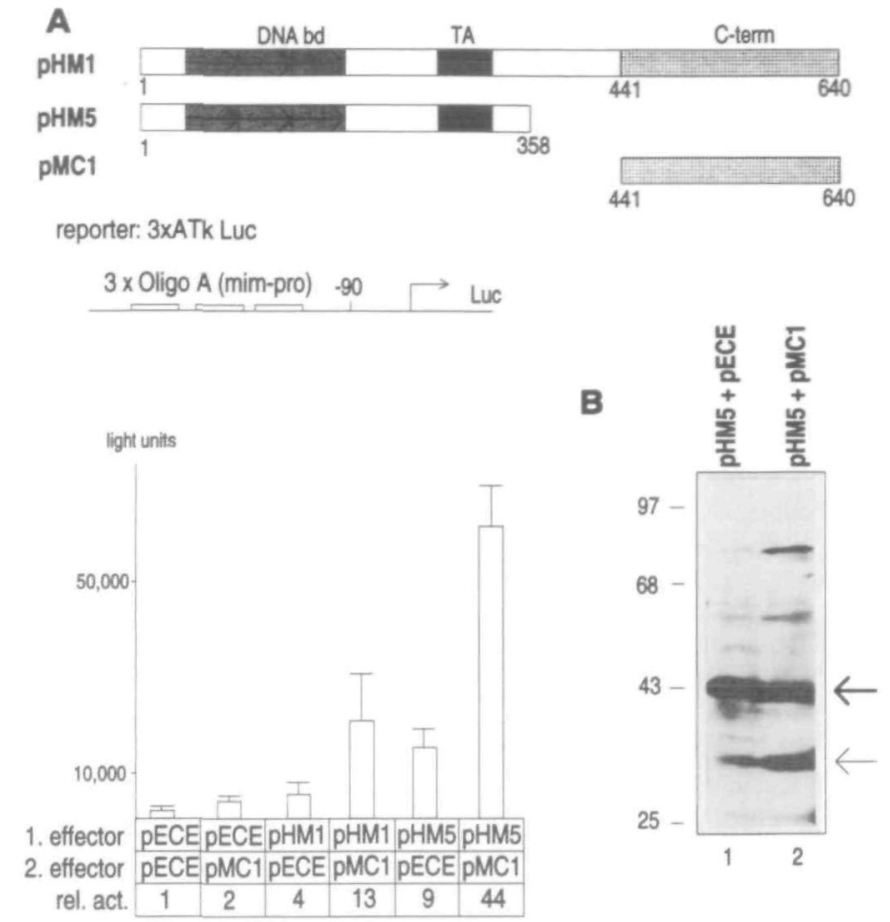

Figure 2. (A) Regulation of transcriptional activity of hu-c-Myb (pHM1) and $\mathrm{C}$-terminal deletion mutant (pHM5) by the C-terminus (pMC1). Schematic diagrams of the proteins tested are shown at the top, the abbreviations are explained in Figure 1. pECE, pHM1, or pHM5 ( $3 \mu \mathrm{g}$ each) as first effector plasmids and pECE or pMCl $(9 \mu \mathrm{g}$ each) as second effector plasmids were cotransfected with the $3 \times$ ATk Luc reporter plasmid $(2 \mu \mathrm{g})$ into adherent HeLa cells. (B) Expression of the C-terminal truncated mutant pHM5 with and without the cotransfection of the C-terminus. COS-7 cells were transfected with $10 \mu \mathrm{g}$ of each indicated effector plasmid. The thick arrow indicates the p42 Myb (pHM5) and the thin arrow C-terminus. Cellular lysate equivalent to $1 \times 10^{6}$ cells were applied per lane. The proteins were detected using a mixture of a rabbit serum directed against the central part of c-Myb (1303) and a rabbit serum directed against the C-terminus (1600). Numbers to the left indicate molecular weight markers in KD.

pHM5 and pVM1 are expressed at only slightly higher levels than the entire c-Myb protein (Figure 1B).

A possible explanation for the enhanced transcriptional activity of C-terminally truncated Myb proteins could be the existence of a negative regulatory factor, which might bind to the $\mathrm{C}$ terminal region of c-Myb. To test this idea, we devised an in vivo competition assay, which is independent of protein expression levels and which is not influenced by the higher DNAbinding affinities of C-terminally truncated Myb proteins (24). An expression vector (pMCl, Figure 2) was constructed containing only the C-terminal aminoacid residues 441 to 640 of the human c-Myb protein. This region corresponds to the sequences deleted in the AMV $\mathrm{v}-\mathrm{Myb}$ protein. It contains a nuclear localization signal (44) but no transactivation domain to avoid squelching effects (45). Furthermore, the heptad leucine repeat is excluded. The importance of this $\mathrm{C}$-terminal region is strengthened by the fact that constructs lacking it result in enhanced transcriptional activity and are capable of transforming haematopoietic cells in vitro $(32,33,34)$.

We transfected the full-length c-Myb (pHM1) and the Cterminally truncated mutant (pHM5) with the $3 \times$ ATk Luc reporter piasmid into HeLa cells (Figure $2 \mathrm{~A}$ ) which leads to 


\section{A}
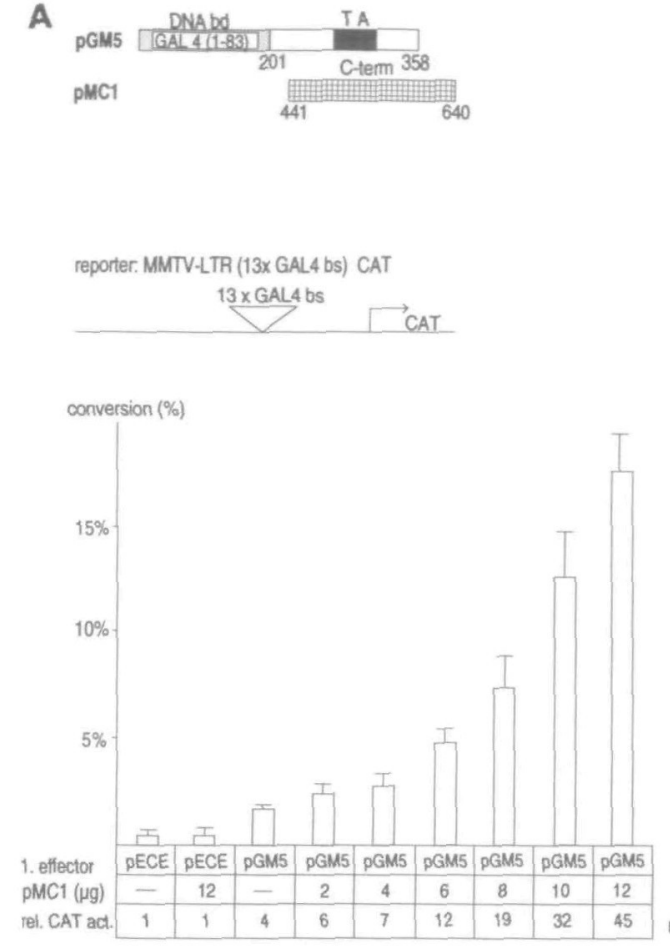

B

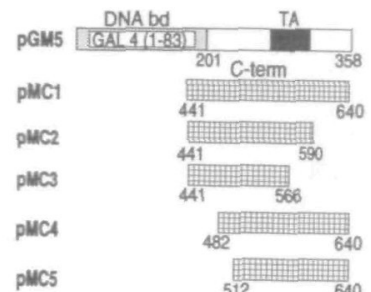

reporter. MMTV-LTR (13X GALL 4 bs) CAT $13 \times$ GALA bS

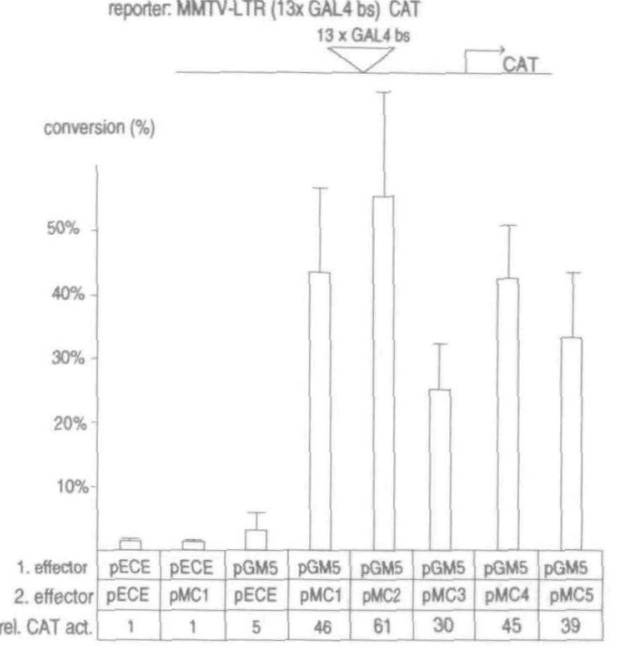

Figure 3. A) Stimulation by the C-terminus in trans is dose-dependent. The top shows a schematic diagram of the proteins used. pGM5 is a GAL4-Myb chimaera containing the GAL4 DNA-binding domain (1-83, grey). Other abbreviations are explained in Figure 1. The reporter consists of an MMTV-LTR CAT construct,

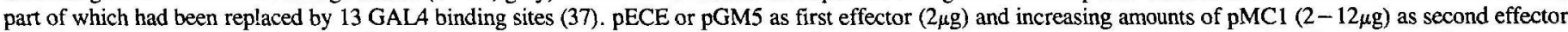
plasmid were catransfected with the MMTV-LTR CAT reporter plasmid $(2 \mu \mathrm{g})$ into adherent HeLa cells. The total amounts of expression plasmids were kept constant by addition of $\mathrm{pECE}$ expression plasmid which was free of insert. CAT assays were performed with $60 \mu \mathrm{g}$ lysates for $50 \mathrm{~min}$. B) Mapping of the regulatory sequences of the C-terminus. The top shows the proteins used. pECE or pGM5 $(4 \mu \mathrm{g})$ as first effector was cotransfected with pECE or pMCl through pMC5 $(12 \mu \mathrm{g}$ each) as second effectors with the MMTV-LTR CAT as reporter plasmid $(2 \mu \mathrm{g})$ into adherent HeLa cells. CAT assays were performed with $60 \mu \mathrm{g}$ lysates for $1 \mathrm{hour}$.

similar results as shown in Figure 1A. Cotransfection of the Cterminus expression construct (pMC1) stimulated the transactivation of both constructs pHM1 and pHM5 about threefold (Figure 2A). This effect was not due to differences in protein expression, since the intensity of the upper band (pHM5) is not altered by cotransfection of the C-terminus expression construct (pMCl) as shown in Figure 2B (lanes 1 and 2). A similar effect was observed with a cytomegalovirus (CMV) promotor instead of a SV40 promotor.

Inhibition of transcriptional activation is mediated by the binding of a potential cellular factor to the $\mathbf{C}$-terminus

In order to optimize the effect shown in Figure 2 we analyzed it systematically by introducing increasing amounts of the Cterminus into the cells. This should result in a dose-dependent enhancement of the transcriptional activity of c-Myb if it titrates out a putative cellular inhibitor. Therefore, increasing amounts of an expression vector coding for the C-terminus ( $\mathrm{pMC1}$ ) were cotransfected with a GAL4-Myb chimaera (pGM5) and an appropriate reporter plasmid, a derivate of the MMTV-LTR CAT construct, part of which had been replaced by 13 GAL4 DNAbinding sites (37) (Figure 3). The GAL4-Myb chimaera was chosen to test whether the effect of the C-terminus depends on the DNA-binding domain of the Myb protein. To exclude nonspecific effects by increasing amounts of promotor sequences these were kept constant by addition of expression vector not containing an insertion. In the absence of cotransfected C- terminus, the GAL4-Myb chimaera activates the reporter fourfold. In the presence of the C-terminus the activation of the reporter is enhanced depending on the concentration up to 45fold, corresponding to an 1 fold activation (Figure $3 \mathrm{~A}$ ). Thus $\mathrm{Myb}$ with its authentic DNA-binding domain as well as GAL4-Myb chimaera can be activated in trans.

In order to further define the negatively regulating sequences of the C-terminus, various constructs containing different portions of the C-terminus were cloned and tested with the GAL4-Myb chimaera pGM5 and the corresponding promotor (Figure 3B). All constructs were capable of enhancing the activated transcription of GAL4-Myb. The constructs define a domain of 55 aminoacid residues located between aminoacid 512 and 566 to be responsible for this effect.

To further confirm the importance of this region a mutant (pMC7) containing an internal deletion of aminoacid residues 495 to 566 was cloned (Figure 4). This mutant was expressed as a fusion protein with aminoacid residues 1 to 147 of GAL4, which contains the sequences necessary for DNA-binding, dimerization and nuclear localization. This was necessary, because one of the nuclear localization signals (44) was deleted in the Myb-mutant. As a control a GAL4-Myb-C-terminus without deletion (pMC6) was cloned. The $3 \times A T k L u c$ plasmid containing no GAL4 binding sites was used as reporter. These constructs were cotransfected with the C-terminally truncated $\mathrm{c}-\mathbf{M y b}$ mutant pHM5, which by itself activates the $3 \times$ ATkLuc promotor ninefold. The construct pMC6 further enhances threefold, leading 

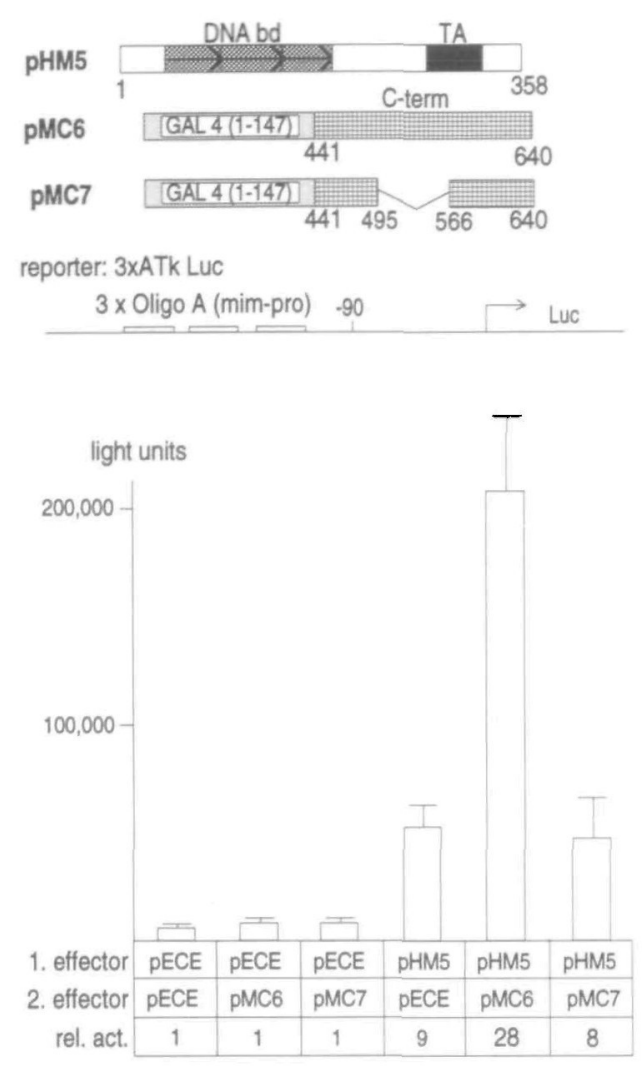

Figure 4. Deletion of the binding site for the cellular factor destroys the stimulatory activity of the C-terminus in trans. The top shows a schematic diagram of the proteins used. pMC6 consists of the GAL4-DNA-binding domain $(1-147$, grey) and the c-Myb C-terminus and pMC7 consists of the GAL4 DNA-binding domain and the $C$-terminus with an internal deletion of aminoacid residues 495-566. Other abbreviations are explained in Figure 1. pECE or pHM5 $(1 \mu \mathrm{g})$ as first effector and pECE, pMC6 or pMC7 $(4 \mu \mathrm{g})$ as second effector plasmids were cotransfected with the $3 \times$ ATk Luc reporter plasmid $(3 \mu \mathrm{g})$ into COS-7 cells.

to 28 fold transactivation, whereas cotransfection of pMC7 is without effect. In a control experiment it was excluded, that the pMC6 construct contains a transactivation domain itself (data not shown).

\section{Investigation of the activity of other domains of the c-Myb protein in trans}

Our data indicate that the C-terminus of human c-Myb enhances the transcriptional activity of various c-Myb constructs in trans in in vivo competition assays. While this work was in progress a study by Dubendorff et al. (28) was published which indicated that the C-terminus of chicken $\mathrm{c}-\mathrm{Myb}$ negatively regulated transcriptional activation in cis and trans. In contrast to the results reported here they used a C-terminal Myb protein which harbored the transactivating domain. In order to test whether the presence of the transactivating domain might account for the differences of the results we tested a GAL4-Myb protein (pGM5) with a reporter containing GAL4 DNA-binding sites (MMTV-LTR$\mathrm{CAT}$ ) and cotransfected Myb expressing plasmids with and without the transactivating domain (Figure 5). The cotransfected Myb proteins contained the authentic DNA-binding domain, thus they did not bind to the reporter and were only active in trans.

The result shows that cotransfection of pGM5 with two constructs which only differ in their transactivating region,

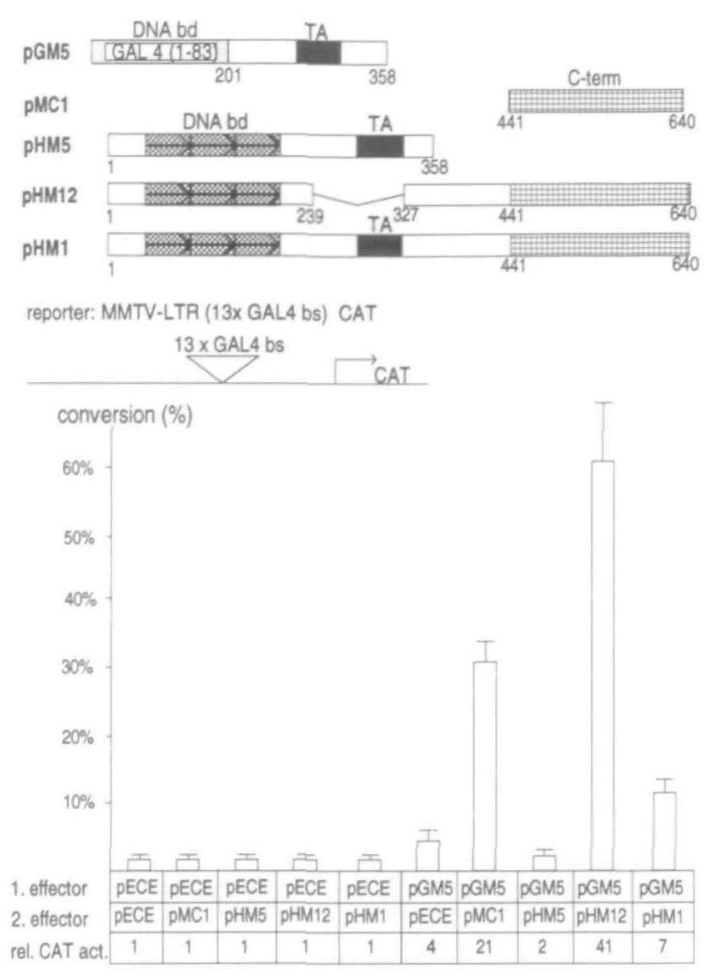

Figure 5. Effect of the transactivating and other domains of the c-Myb protein in trans. The top shows a schematic diagram of the proteins used. pHM12 has an internal deletion of aminoacid residues 239 to 327 , which harbors the transactivation domain. pECE or pGM5 $(4 \mu \mathrm{g})$ as first effector and pECE, pMCl,

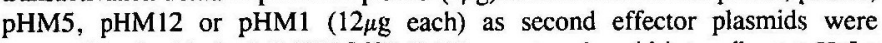
cotransfected with the MMTV-LTR CAT reporter plasmid into adherent HeLa cells. CAT assays were performed with $30 \mu \mathrm{g}$ lysates for $30 \mathrm{~min}$.

pHM12 and pHM1, lead to different degrees of stimulation in trans. Whereas pHM1 has nearly no stimulatory effect in trans, pHM12 without the transactivating domain stimulates tenfold. A construct containing the transactivation but not the C-terminus (pHM5) supressed the transactivation by pGM5 to nearly basal level. This effect is even stronger, when a greater excess is used (data not shown). The result demonstrates, that transactivating domains can interfere by squelching in trans. Squelching has been described for various transcription factors in transient transfection assays and in vitro transcription assays with nuclear extracts (45). In the entire c-Myb the stimulatory effect of the C-terminus seems to be compensated for by the squelching activity of the transactivating domain. Therefore, the squelching activity of the transactivation domain could be involved in the differences between the results reported here and those reported by Dubendorff et al. (28).

\section{The C-terminus enhances transcriptional activity of various transactivators}

To map the region of the Myb protein which responds to the cotransfected C-terminus and led to enhanced transactivation, a GAL4-Myb construct was used which codes only for the acidic domain corresponding to aminoacid residues 275 to 327 of hu$\mathrm{c}-\mathrm{Myb}(10)$. This region was fused to GAL4 (1 to 147) (Figure $6 \mathrm{~A}, \mathrm{pGM} 12$ ) and cotransfected with the C-terminus using the appropriate MMTV-LTR with the GALA binding sites as a 

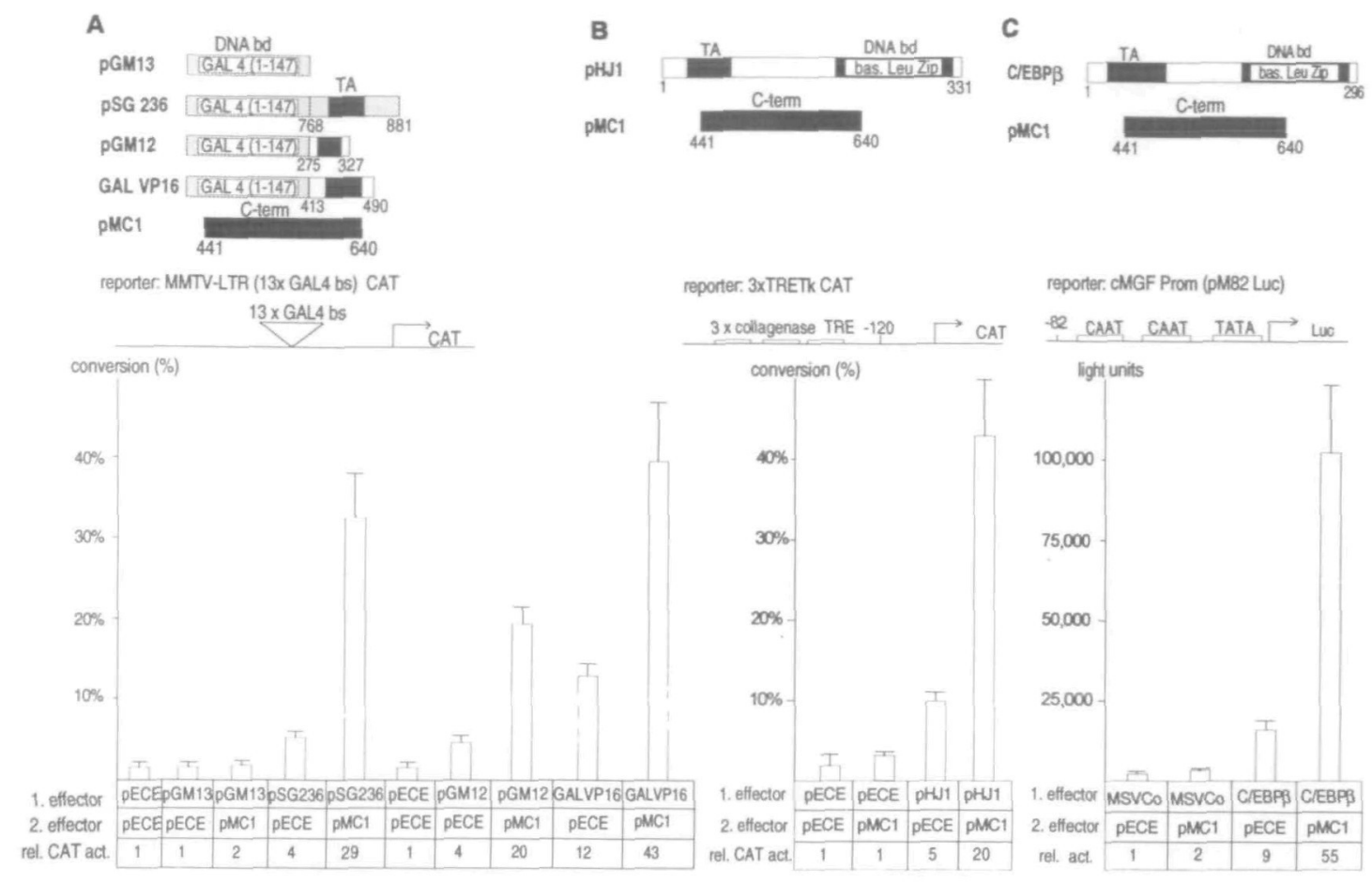

Figure 6. The C-terminus stimulates transcriptional activity of various transactivators. Schematic diagrams of the proteins tested are shown on top. (A) pGM13 contains the DNA-binding domain of GALA $(1-147)$, pSG236 consists of GALA DNA-binding domain (1-147) and the GAL4 transactivating domain II (768-881). pGM12 contains the GAL4 DNA-binding domain and the transactivating domain of hu-c-Myb (275-327) and GAL4-VP16 consists of the GAL4 DNA-binding domain and the VP16 transactivation domain (413-490). pECE, pGM13, pSG236, pGM12 or GAL4-VP16 (500ng each) as first effector and pECE or pMCl (8 $\mu$ g) as the second effector plasmids were cotransfected with the MMTV-LTR CAT reporter plasmid into adherent HeLa cells. CAT-assays were performed for $15 \mathrm{~min}$ with $30 \mu \mathrm{g}$ cell lysates for cells transfected with pGM13, pSG236 and the control pECE, whereas $5 \mu \mathrm{g}$ cell lysates from cells transfected with pGM12, GAL4-VP16 and the control pECE were analyzed for $5 \mathrm{~min}$. (B) pHJl represents the hu-c-Jun containing the basic region and leucin zipper (bas. Leu Zip) as DNA-binding domain. The reporter plasmid $3 \times$ TRETk CAT consists of a three times repeated TRE element of the collagenase promotor upstream of a Tk minimal promotor with the CAT gene. pECE or pHJ1 $(3 \mu \mathrm{g})$ as first effector and pECE or pMC1 $(4 \mu \mathrm{g})$ as second effector plasmids were cotransfected with $3 \times$ TRETk CAT $(1 \mu \mathrm{g})$ as reporter plasmid into adherent HeLa cells. CAT assays were performed with $30 \mu \mathrm{g}$ lysates for $30 \mathrm{~min}$. C) C/EBP $\beta$ represents the rat clone containing the basic region and leucin zipper (bas. Leu Zip) as DNA-binding domain. The reporter plasmid pM82Luc is based on the cMGF promotor (42), containing two CAAT boxes in front of a luciferase gene. An MSV control plasmid without insert or MSV C/EBP $\beta(2 \mu \mathrm{g})$ as first effector plasmids and pECE or pMC1 (5 $\mu \mathrm{g})$ as second effector plasmids were cotransfected with pM82Luc $(3 \mu \mathrm{g})$ as reporter plasmid into adherent HeLa cells.

reporter. The C-terminus stimulates the activity of the pGM12 construct fivefold whereas the GAL4 (1-147) (pGM13) which shows no transactivating activity is not stimulated by the $C$ terminus. The result shown in Figure 6A indicates that the acidic domain is essential for the response to the cotransfected Cterminus.

Other transactivators with acidic transactivating domains were tested. A GAL4 construct with its authentic transactivating domain II fused to GAL4 $(1-147)$ as well as a GAL4-VP16 fusion protein were chosen as examples and analyzed with and without cotransfection of the c-Myb C-terminus. The results show that these two transactivators are also further activated 7- and 3.5 -fold, respectively (Figure 6A).

To test the effect of the C-terminus on native transactivators we coexpressed the c-Myb C-terminus with human c-Jun (pHJ1) and a reporter plasmid with a CAT gene under the control of three TPA response elements (TRE) upstream of a thymidine kinase minimal promotor $(3 \times$ TRETk CAT). This reporter construct was stimulated fivefold by c-Jun, an activation which was further enhanced fourfold by cotransfection of the C-terminus of c-Myb in trans (Figure 6B).

In addition the effect of the C-terminus with the CCAAT-box binding protein $\mathrm{C} / \mathrm{EBP} \beta$ (40) was tested, it contains no acidic cluster but proline-rich segments in its aminoterminus. A MSV C/EBP $\beta$ construct activates the pM82Luc reporter plasmid (42), consisting of only two CAAT-boxes and a TATA-box. C/EBP $\beta$ stimulates the activity of this reporter ninefold, an effect which is further enhanced sixfold by the C-terminus in trans (Figure 6C).

In addition other than $\mathrm{HeLa}$ and $\mathrm{COS}$ cells such as $\mathrm{CHO}$ and $\mathrm{NIH} / 3 \mathrm{~T} 3$ cells were tested, all of which led to enhanced transactivation by the C-terminus (data not shown).

\section{Human B-Myb is not regulated by the putative cellular} inhibitor

In human hematopoietic cells B-Myb is expressed in addition to c-Myb during the Gl/S boundary of the cell-cycle (46). In experiments using antisense oligodeoxynucleotides it has been shown that the expression of B-Myb is essential for proliferation of human hematopoietic cells and BALB/c 3T3 fibroblasts $(41,47)$. Therefore we asked, whether B-Myb was regulated by the same mechanism as c-Myb involving a putative cellular inhibitor as well. For that purpose the human c-Myb (pHM1) and $\mathrm{B}-\mathrm{Myb}(\mathrm{pBM} 1)$ were coexpressed with or without the C- 
A
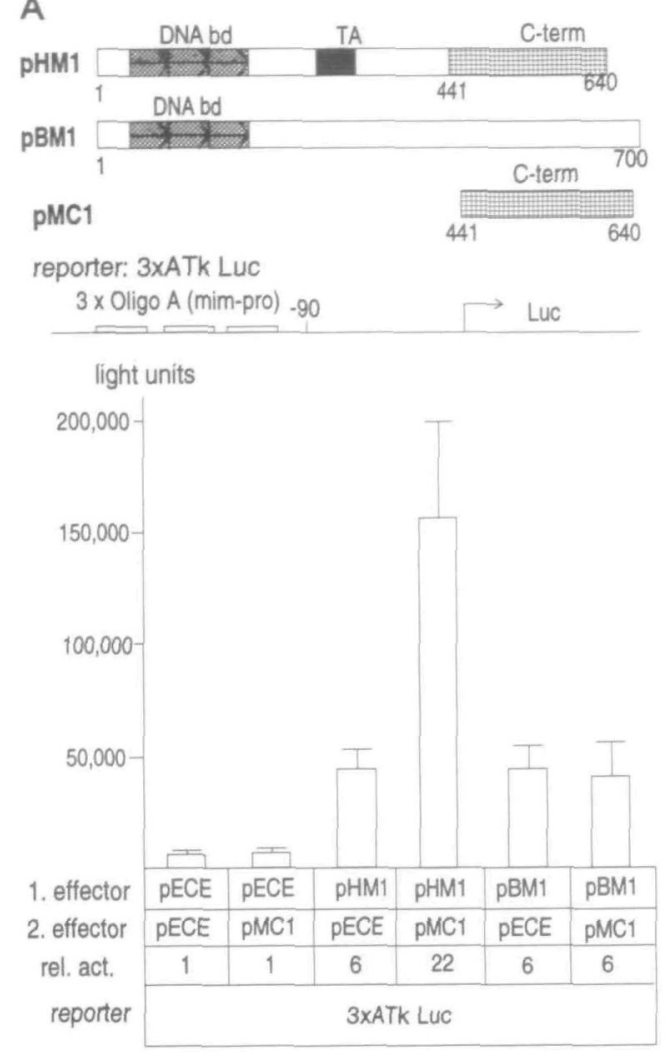

B
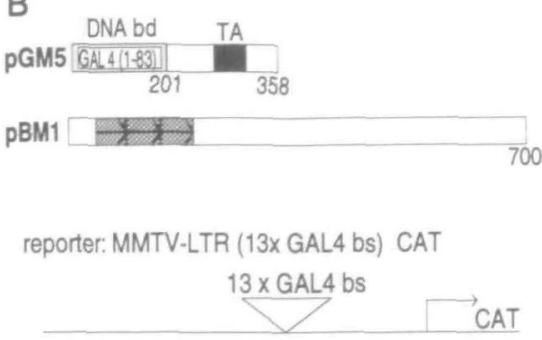

conversion (\%)

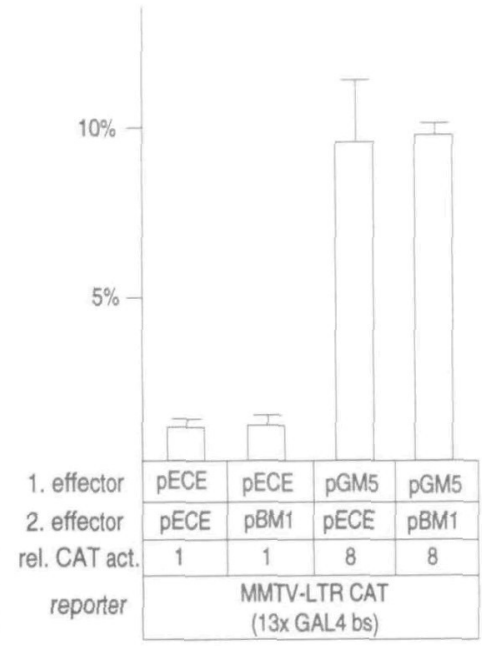

Figure 7. Human B-Myb is not regulated by the C-terminus of c-Myb in trans. The proteins used are schematically shown on top. pBM1 represents the human B-Myb which does not contain an acidic cluster but a large region with acidic amino acid residues. (A) pECE, pHM1 or pBM1 ( $3 \mu \mathrm{g}$ each) as first effector and pECE or pMC1 $(9 \mu \mathrm{g})$ as second effector plasmids were cotransfected with the $3 \times$ ATk luciferase reporter plasmid ( $3 \mu \mathrm{g})$ into COS-7 cells.(B) pECE or pGM5 $(2 \mu \mathrm{g})$

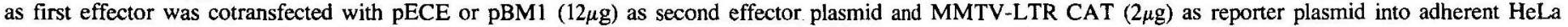
cells. CAT assays were performed with $60 \mu \mathrm{g}$ cell lysates for 1 hour and normalized in respect of transfection efficiencies.

terminus of c-Myb and the $3 \times$ ATk Luc reporter plasmid. c- and $\mathrm{B}-\mathrm{Myb}$ activate the promoter under these conditions sixfold, yet only the activity of $\mathrm{c}-\mathrm{Myb}$ is enhanced by the coexpressed $\mathrm{C}$ terminus 3.5-fold (Figure 7A). B- and C-Myb activates under these conditions in a DNA-binding dependent way, since both constructs do not activate a control plasmid lacking the Myb binding sites nor is this effect stimulated by the C-terminus in trans (data not shown). Thus, B-Myb does not seem to be regulated by the same mechanism as c-Myb. A sequence comparison of the two proteins indicates that B-Myb although containing a large negatively charged region lacks an acidic cluster corresponding to the transactivating domain in c-Myb.

In order to investigate whether B-Myb transactivates by a different mechanism than c-Myb, we tested whether B-Myb was able to interfere with $\mathrm{c}-\mathrm{Myb}$ transactivation by squelching a cellular factor. Therefore we cotransfected the GAL4-c-Myb construct pGM5 with its appropriate reporter plasmid MMTVLTR-CAT, which contains GAL4 binding sites, with or without a construct expressing human B-Myb. This construct was unable to influence the GALA-c-Myb transcriptional activity (Figure 7B). In contrast the transactivating domain of VP16 was able to downregulate the activity of c-Myb (data not shown).

This result indicates that B-Myb contains a different type of transactivating domain than that of the other transcription factors tested.

\section{DISCUSSION}

We present evidence that the C-terminus as part of the human c-Myb protein is a negatively regulating domain. In comparison to the entire $\mathrm{c}-\mathrm{Myb}$ protein containing the $\mathrm{C}$-terminus in cis, a C-terminal deletion mutant has an increased transcriptional activity (Figure 1) as reported before $(10,28)$. To our surprise the C-terminus enhances the transcriptional activity when expressed separately and supplied in trans (Figure 2,3). In vivo competition assays suggest that the regulatory activity of the $\mathrm{C}$ terminus is due to the binding of a putative negative cellular inhibitor, which can be titrated out as shown by the dosedependent enhancement (Figure 3A). The putative cellular inhibitor apparently interacts with the region between aminoacid 512 and 566 on the C-terminus, which was shown by overlapping amino- and carboxyterminal truncated mutants of the C-terminus and by an internal deletion of this region in a GAL4-C-terminus fusion protein (Figure 4, pMC7). Computer analysis predict that this region, which is highly conserved in human, mouse and chicken c-Myb proteins and also in human A-Myb (13), is on the surface of the $\mathrm{c}-\mathrm{Myb}$ protein. This region is deleted in both AMV and E26 v-Myb and in oncogenic activated forms of cMyb found in different transformed cell lines $(29,30,31)$. Furthermore deletion of this region results in an oncogenic activation in transformation assays in vitro $(32,33,34)$. 


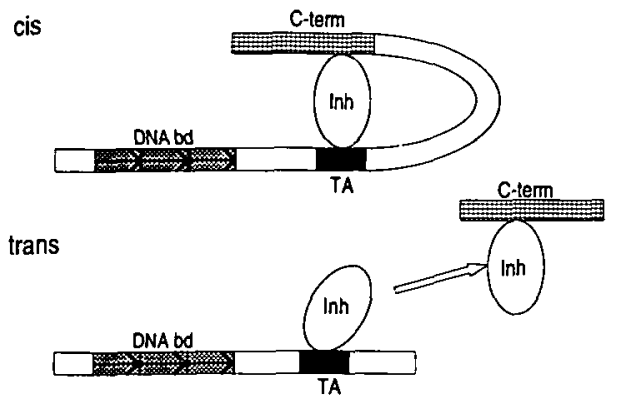

Figure 8. Model for the regulatory activity of the C-terminus in cis and trans. The domains are marked as in Figure 1, the putative cellular inhibitor is marked by Inh. When the $\mathrm{C}$-terminus is present in cis, a universal cellular inhibitor binds to the C-terminus as well as to the transactivating domain and downregulates transcription. Truncation of the C-terminus destabilizes binding of the inhibitor to the transactivating domain which leads to increase of transcriptional activity. Presence of the C-terminus in trans sequester away the inhibitor thereby further increasing transcriptional activity. The inhibitor acts on transactivating domains of several transcription factors.

The stimulatory effect in trans was also tested with the entire c-Myb protein instead of the C-terminus in cotransfection assays. The situation is here somehow more complex due to superposition of a stimulating effect caused by the C-terminus and downregulation of transcription by the transactivating domain present on the cotransfected c-Myb presumably by squelching (Figure 5). Therefore, c-Myb has nearly no stimulatory effect in trans, whereas removal of the transactivating domain in cMyb results in an even stronger enhancement of transactivation than that of the C-terminus in trans.

The region of the $\mathrm{c}-\mathrm{Myb}$ protein which responds to the cotransfected C-terminus was mapped to the acidic transactivation domain of the Myb protein (aminoacid residues 275-327). This domain if linked to the heterologous DNA-binding domain of the GAL4 protein is sufficient for the enhancement by the Cterminus (Figure 6A). In addition, other transactivators like $\mathrm{G}$ AL4 with its homologous transactivating domain II, a GAL4-VP16 chimaera, c-Jun or C/EBP $\beta$ can be stimulated (Figure $6 \mathrm{~A}, 6 \mathrm{~B}, 6 \mathrm{C}$ ). It should be determined whether these activators have a structural motif in common.

In contrast, transactivation by the human B-Myb is not further enhanced by cotransfection of the C-terminus of c-Myb. Therefore B-Myb does not seem to be regulated by the same putative inhibitor. B-Myb is furthermore not able to interfere with the transcriptional activity of a GALA-c-Myb chimaeric protein (Figure 7). Therefore it seems likely that B-Myb transactivates by a mechanism different from c-Myb. Interestingly, human BMyb contains a glutamine rich domain and a large region with an overall negative charge, but no acidic cluster characteristic for acidic transactivating domains like c-Myb (18).

The data described here resemble those on regulation of the c-Jun protein by a presumptive cell-specific inhibitory factor that reduces its transcriptional activity $(48,49)$. Other transcriptional activators such as a yeast heat-shock factor and the p53 geneproduct also contain an inhibitory region in addition to the transactivating domain $(50,51)$.

The transactivating domain and the C-terminus may both interact with the putative cellular inhibitor in the full-length protein by forming a bridge-type structure as indicated in the model (Figure 8). Since the two domains are not adjacent to each other, the model suggests a bent $\mathrm{C}$-terminus. This would enable it to get in close contact to the transactivating domain. The reason why the model suggests direct binding of the inhibitor not only to the C-terminus but also to the transactivating domain is due to the observation that $\mathrm{c}-\mathrm{Myb}$ proteins in which the $\mathrm{C}$-terminus has been truncated exhibit enhanced transactivation activity when the C-terminus is supplied in trans. In order to explain how the c-Myb lacking the C-terminus exhibits a higher transactivation activity than the full-length protein (Figure 1), one has to assume that binding of the inhibitor to the transactivation domain alone is destabilized due to loss of the second binding site on the $\mathrm{C}$ terminus.

This model, in which the negative regulatory effect is attributed to a cellular factor, is supported by a publication of Chen and Lipsick (52), who showed that in yeast the entire c-Myb protein had the same activity as a C-terminally truncated protein. It seems therefore likely that the negative regulatory effect of the $\mathrm{C}$ terminus in cis is caused by the interaction with a cellular factor specific for higher eukaryotes.

Recently Dubendorff et al. (28) have taken a similar approach as described here to characterize the carboxyterminal region of chicken c-Myb. They also tested its function in trans but observed a decrease of transactivation activity. Their experiments differ from the ones described here in that they used a different reporter system consisting of nine Myb binding sites and a TATA box activated by a v-Myb-VP16 chimaera. Furthermore they used a larger part of the Myb protein fused to GALA which comprised not only the two negatively regulating domains but also the transactivating domain which might have caused squelching. In addition, the fusion to GALA allows dimer formation. In our experiments (Figure 5) a construct containing the transactivation domain but not the $\mathrm{C}$-terminus reduces the transactivation in trans by squelching. In the entire c-Myb the stimulatory effect of the C-terminus is nearly completely compensated for by the squelching effect of the transactivation domain. Thus, the superposition of these opposing effects might account for the differences. Since the stimulatory effect of the C-terminus in trans (Figure 2) and the the squelching effect are both dose-dependent (data not shown), this experimental system is extremely sensitive to experimental conditions and to differences in the concentration of the putative inhibitor in the cells used. Therefore, since Dubendorff et al. (28) used QT6 quail fibroblasts as recipient cells, differences in the concentration of the potential inhibitory factor between the avian and mammalian cells might also play a role. In addition, other cell-specific factors could also be involved. These potential differences between the avian and the human system were not the scope of the present study, but could be of interest for resulting studies.

The fact that the stimulating activity is not restricted to the cMyb protein but of no effect on the basal activity of the reporter, we suppose that the inhibitory factor is involved in regulation of activated but not basal transcription. Transcription factors stimulate the transcription by the RNA-polymerase II by interacting with a multiprotein complex including the general transcription factors TFIIA, B, D, E, F, H, J and additional associated proteins $(53,54)$. Some of the associated proteins may function as adapter molecules between the activators and the general transcription complex, for example the TAF 110 (TBP associated factor) interacts specifically with the activation domains of SP1 (55). In addition, inhibitory factors involved in transcriptional regulation have been described in human and yeast 
cells such as NC1, NC2, Dr1, Dr2 and ADI $(56,57,58,59)$ which interfere with the binding of TBP or the association of TFILA or TFIIB.

The data presented here suggest that a cellular inhibitory factor may directly interact with the transactivating domain as well as with the C-terminus of hu-c-Myb and negatively regulate the transcriptional activity of c-Myb. The inhibitor seems to interfere with a factor-specific stimulation step of the transcription complex formation, since it interacts with the transactivating domain of c-Jun, C/EBP $\beta$, GAL4, VP16, and c-Myb but not of human BMyb. Since the C-terminus sequesters away the putative inhibitor from the initiation complex, the stimulatory effect in trans is only dependent on the concentration of the C-terminus. Binding of a transcription factor to a universal inhibitor would represent a new type of regulation of transactivation. Deletion of one of the two binding sites as in the case of $v-M y b$ could cause a reduction and destabilization of the binding of the inhibitor to the second site. We therefore tested the effect of the C-terminus fused to $\mathrm{v}-\mathrm{Myb}$. The fusion results in a reduction of the transactivation activity to a level comparable to c-Myb (data not shown). This result demonstrates, that the fusion of the C-terminus to another transcription factor leads to an inhibition of its activity. Therefore the deletion of the C-terminus could be one reason for the transforming activity of $\mathrm{v}-\mathrm{Myb}$.

It will be the scope for following studies, to investigate whether the fusion of the c-Myb C-terminus to other transcription factors like VP-16 will result in inhibition of their transactivation activity in cis and whether the C-terminus when bound to DNA can transrepress the activity of an activated promotor.

The stimulatory effect of the C-terminus of c-Myb in trans could in addition explain the fact that Myb can induce the expression of genes which have no Myb-binding sites in their promotor sequence $(60,19)$. In the case of the HSP70 promotor only a special type of TATA box and the binding of another transcription factor are necessary for stimulation of Myb protein in trans. This situation could be explained by the titration of a cellular factor like the one described here.

\section{ACKNOWLEDGEMENTS}

The authors are indebted to Dr M.Ptashne, Dr I.Sadowski, Dr T.Graf, Dr P.Angel, Dr S.L.McKnight, Dr A.Leutz, and to Dr M.Introna for supplying plasmids. This work was supported by the Deutsche Forschungsgesellschaft, the Dr Mildred Scheel Stiftung and the Vaillant Stiftung.

\section{REFERENCES}

1. Klempnauer, K.-H., Gonda. T.J. and Bishop, J.M. (1982) Cell, 31, 453-463.

2. Radke, K., Beug, H., Komfeld, S. and Graf, T. (1982) Cell, 31, 643-653.

3. Klempnauer, K.-H., Symonds, G., Evan, G.I. and Bishop, J.M. (1984) Cell, $37,537-547$

4. Biedenkapp, H., Borgemeyer, U., Sippel, A.E. and Klempnauer, K.-H. (1988) Nature, 335, 835-837.

5. Howe, K.M. and Watson, R.J. (1991) Nucleic Acids Res., 19, 3913-3919.

6. Ness, S.A., Marknell, A. and Graf, T. (1989) Cell, 59, 1115-1125.

7. Zobel, A., Kalkbrenner, F., Guehmann, S., Nawrath, M., Vorbrueggen, G. and Moelling, K. (1991) Oncogene, 6, 1397-1407.

8. Dasgupta, P., Saikumar, P., Reddy, D. and Reddy, E.P. (1990) Proc. Natl. Acad. Sci. USA, 87, 8090-8094.

9. Weston, W. and Bishop, J.M. (1989) Cell, 58, 85-93

10. Kalkbrenner, F., Guehmann, S. and Moelling, K. (1990) Oncogene, 5, $657-661$.

11. Nishina, Y., Nakagoshi, H., Imamoto, F., Gonda, T.J. and Ishii, S. (1989) Nucleic Acids Res., 17, 107-117.
12. Klempnauer, K.-H., Amold, H. and Biedenkapp, H. (1989) Genes and Dev. $3,1582-1589$.

13. Nomura, N., Takahashi, M., Matsui, M., Ishii, S., Date, T., Sasamoto, S. and Ishizaki, R. (1988) Nucleic Acids Res., 16, 11075-11089.

14. Lam, E.W.F., Robinson, C. and Watson, R.J. (1992) Oncogene, 7, $1885-1890$.

15. Bouwmeester, T., Guehmann, S., El-Baradi, T., Kalkbrenner, F., van Wijk, I., Moelling, K. and Pieler, T. (1992) Mech. Dev., 37, 57-68.

16. Foos, G., Grimm, S. and Klempnauer, K.-H. (1992) EMBO J., 11 4619-4629.

17. Mizuguchi, G., Nakagoshi, H., Nagase, T., Nomura, N., Date, T., Ueno, Y. and Ishii, S. (1990) J. Biol. Chem., 265, 9280-9284

18. Nakagoshi, H., Takemoto, Y. and Ishii, S. (1993) J. Biol. Chem., 268, $14161-14167$

19. Foos, G., Natour, S. and Klempnauer, K.-H. (1993) Oncogene, 8, $1775-1782$.

20. Klempnauer, K.-H., Ramsay, G., Bishop, J.M., Moscovici, M.G., Moscovici, C., McGrath, J.P. and Levinson, A.D. (1983) Cell, 33, 345-355.

21. Ibanez, C.E. and Lipsick, J.S. (1988) J. Virol., 62, 1981-1988.

22. Lipsick, J.S. and Ibanez, C.E. (1987) J. Virol., 61, 933-936.

23. Stober-Grässer, U. and Lipsick, J.S. (1988) J. Virol., 62, 1093-1096.

24. Ramsey, R.G., Ishii, S. and Gonda, T.J. (1992) J. Biol. Chem., 267, $5656-5662$

25. Sakura, H., Kanei-Ishii, C., Nagase, T., Nakagoshi, H. and Gonda, T.J (1989) Proc. Natl. Acad. Sci. USA, 86, 5758-5762.

26. Kanei-Ishii, C., MacMillan, E.M., Nomura, T., Sarai, A., Ramsay, R.G. Aimoto, S., Ishii, S. and Gonda, T.J. (1992) Proc. Natl. Acad. Sci. USA 89, 3088-3092.

27. Nomura, T., Sakai, N., Sarai, A., Sudo, T., Kanai-Ishii, C., Ramsey, R.G., Favier, D., Gonda, T.J. and Ishii, S. (1993) J. Biol. Chem., 268 21914-21923.

28. Dubendorff, J.W., Whittaker, L.J., Eltman, J.T. and Lipsick, J.S. (1992) Genes and Dev., 6, 2524-2535.

29. Weinstein, Y., Ihle, J.N., Lavu, S. and Reddy, E.P. (1986) Proc. Natl. Acad. Sci. USA, 83, 5010-5014.

30. Shen-Ong, G.L.C., Morse, H.C., Potter, M. and Mushinski, J.F. (1986) Mol. Cell. Biol., 6, 380-392.

31. Gonda, T.J., Corey, S., Sobieszczuk, P., Holtzmann, D. and Adams, J.M. (1987) J. Virol., 61, 2754-2763.

32. Gonda, T.J., Buckmaster, C. and Ramsay, R.G. (1989) EMBO J., 8, $1777-1783$

33. Grässer, F.A., Graf, T. and Lipsick, J.S. (1991) Mol. Cell Biol., 11 , $3987-3996$.

34. Hu, Y., Ramsey, R.G., Kanei-Ishii, C., Ishii, S. and Gonda, T.J. (1991) Oncogene, 6, 1549-1553.

35. Ellis, L., Clauser, E., Morgan, D.O., Edery, M.R., Roth, A. and Rutter, W.J. (1986) Cell, 45, $721-732$

36. Sadowski, I. and Ptashne, M. (1989) Nucleic Acids Res., 17, 7539

37. Sadowski, 1., Ma, J., Triezenberg, S. and Ptashne, M. (1988) Nature, 335 $563-564$.

38. Carey, M., Lin, Y-S., Green, M.R. and Ptashne, M. (1990) Nature, 345 $361-364$.

39. Angel, P., Hattori, K., Smeal, T. and Karin, M. (1988) Cell, 55, 875-885

40. Cao, Z., Umek, R.M. and McKnight, S.L. (1991) Genes and Dev., 5, $1538-1552$.

41. Arsura, M., Introna, M., Passerini, F., Mantovani, A. and Golay, J. (1992) Blood, 79, 2708-2716.

42. Sterneck, E., Müller, C., Katz, S. and Leutz, A. (1992) EMBO J., 11, $115-126$.

43. De Wet, J.R., Wood, K.V., DeLuca, M., Helinski, D.R. and Subramani S. (1987) Mol. Cell. Biol., 7, 725-737.

44. Dang, C.V. and Lee, W.M.F. (1989) J. Biol. Chem., 264, 18019-18023

45. Lewin, B. (1990) Cell, 61, 1161-1164

46. Golay, J., Capucci, A., Arsura, M., Castellano, M., Rizzo, V. and Introna, M. (1991) Blood, 77, 149-158

47. Sala, A. and Calabretta, B. (1992) Proc. Natl. Acad. Sci. USA, 89 , 10415- 10419.

48. Baichwal, V.R. and Tjian, R. (1990) Cell, 63, 815-825

49. Baichwal, V.R., Park, A. and Tjian, R. (1992) Genes and Dev., 6, 1493-1502.

50. Nieto-Sotelo, J., Wiederrecht, G., Okuda, A. and Parker, C.S. (1990) Cell, 62, 807-817

51. Liu, X., Miller, C.W., Koeffler, P.H. and Berk, A.J. (1993) Mol. Cell. Biol., 13, 3291-3300.

52. Chen, R.-H. and Lipsick, J.S. (1993) Mol. Cell. Biol., 13, 4423-4431 
53. Zawel, L. and Reinberg, D. (1992) Current Opinion in Cell Biology, 4, 488-495.

54. Hernandez, N. (1993) Genes and Dev., 7, 1291-1308.

55. Hoey, T., Weinzierl, R.O.J., Gill, G., Chen, J.-L., Dynlacht, B.D. and Tjian, R. (1993) Cell, 72, 247-260.

56. Meisterernst, M., Roy, A.L., Lieu, H.M. and Roeder, R.G. (1991) Cell, $66,981-993$.

57. Meisterernst, M. and Roeder, R.G. (1991) Cell, 67, 557-567.

58. Inostroza, J.A., Mermelstein, F.H., Ha, I.H., Lane, W.S. and Reinberg, D. (1992) Cell, 70, 477-489.

59. Auble, D.T. and Hahn, S. (1993) Genes and Dev., 7, 844-856.

60. Nakano. T. and Graf T. (1992) Oncogene, 7, 527-534. 